\title{
Knowing Stillness
}

\section{Penelope Moore}

Daisy: I'm totally into this thing of whatever you're doing, just being there and being yourself. I mean, not trying to do something above or below, just trying to be very honest and very open. In a performance the best and the strongest performance is always when you are extremely relaxed. Being relaxed is not about being lethargic - it's just about being relaxed and then you are incredibly aware and incredibly there, and all your deepest power comes through.

Margaret: Nothing is inhibiting that flow.

Daisy: Yes...so it doesn't matter so much if you've practised or not actually; it's how you feel at that moment.

Yu: It's how you feel, yeah, completely!

Daisy: You just live. And if you let anything that happens... Because for me the strongest challenge in a concert, just like anything in life, isanytime I make a mistake, it doesn't matter. And you look at the next moment as if that moment [of making a mistake] hasn't come. Because then you're only in the next moment. And the audience-if you live like that - the audience will never even notice you've made a mistake. And if you don't live like that and you don't perform like that, they will not notice you've made a mistake either, but they will not feel that things are so powerfully coming across any more because they will know that you're somewhere else, you're not so there.

Yu: Well, you're in the negative. You're being pulled by this having made a mistake thing. [Yu mimes pulling a string behind her head, as if it was attached to her and pulling her backwards. $]^{1}$ 


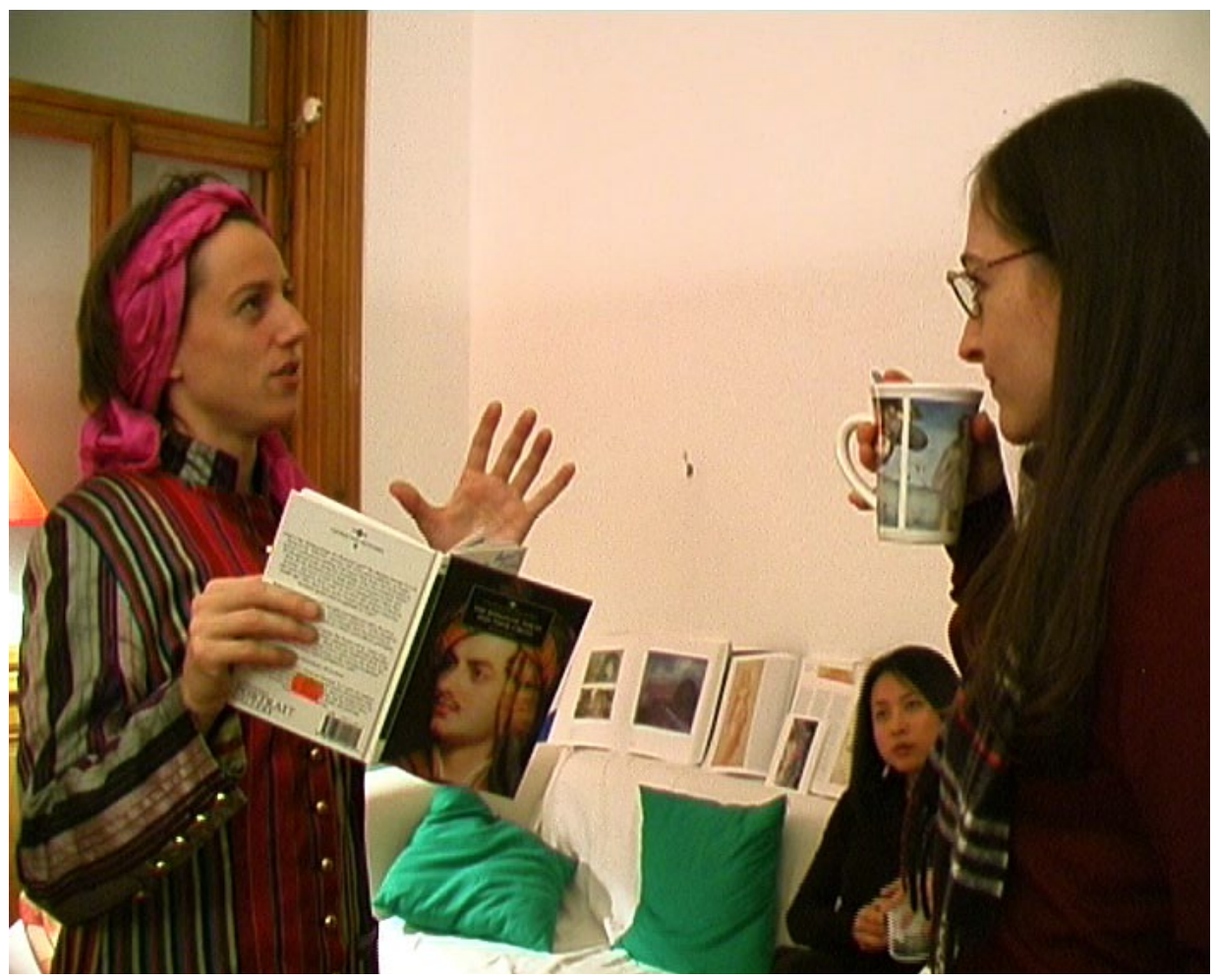

Figure 1 Still image from Introductory Sequence

View Introductory Sequence: 'Being Yourself'2

\section{Introduction}

This article draws on ethnographic work with professional musicians in Vienna to explore the activity of musical performance. ${ }^{3}$ In particular, I draw on my work in both film and text to identify and elucidate a skilled practice by which professional musicians are able to produce great performances with consistency. Performance is not just a matter of technical acuity in playing an instrument. It is a communicative act that involves the bringing together of a diverse range of skills, techniques, practices and abilities while playing. Musicians hold such knowledge at different levels of awareness, bringing aspects of it to consciousness as needed while they play. In and through this article, I argue

2 View associated media files via the ANU E Press website at http://epress.anu.edu.au/titles/humanitiesresearch-journal-series/humanities-research-vol-xviii-no-1-2012

3 My understanding of the musicians and their lives is based on eighteen months of fieldwork in Vienna conducted from 2002 to 2004; however, it also encompasses prior ethnographic research extending back to 1996. 
that, during performance, connections are made between actions, perceptions, thoughts and intentions that only emerge in a kind of stillness. This 'stillness' facilitates a communicative performance.

In this article, I demonstrate the concept and practice of 'stillness' as they hold significance in the lives of the musicians I worked with. I do this by drawing connections through a variety of different ethnographic material, both filmic and written. I show how thinking with a camera, and working with the strengths of filmmaking processes, allowed me to arrive at and elaborate the concept of 'stillness'. In my exploration of stillness, I use different ethnographic examples - some audiovisual, some written - to access knowledge that is not conventionally found through text and processes of writing. This provides an example of how we can know things differently through the visual and through an engagement with different kinds of material thinking - specifically in this case, the materiality of film and filmmaking processes. ${ }^{4}$

What I am calling 'stillness' is characterised by the ability to make many different elements come together in synthesis at the right moments. In developing the concept of stillness, I endeavour to show it to be a skilled process, linked to a way of being, through which years of making music and the diversity of skills this involves are gathered into the moments of playing. Stillness, which I link with 'being-in-the-moment' (a turn of phrase that some musicians do use), is, paradoxically, filled with a history of professional and non-professional activity, technical practice and previous performance experiences. ${ }^{5}$ Therefore, stillness should not be associated with an absence of activity but, rather, configured as the concentration of a diverse history of activity, tailored to the task at hand. The time it takes to learn a musical piece, and all the tasks and associated skills that go into it, is hidden in the moments of playing.

Bringing aspects of musical knowledge to consciousness in the moments when they are most needed involves being responsive to the changing environment during the stream of performance activity. To do this requires holding a practised awareness of body and being and the particular transformations that music making affords. At the same time, it involves musicians maintaining a confidence in their own ability to play the music so that, in the moments of

4 In my research, I used a digital video camera to do my filming. In this article, the term 'film' is also intended to encompass digital and/or video material, equipment and processes.

5 In using the term 'being-in-the-moment', I am conscious of the work of philosophers such as Heidegger and Merleau-Ponty who have discussed being in great depth. While phenomenology and existential anthropology have provided inspiration for me throughout my research, my decision to use terms like 'beingin-the-moment' stems primarily from discussions I had with musicians during fieldwork, since this is part of the language that they themselves use when trying to express their own experiences and practices of music making. In this article, I focus on developing an understanding of their music worlds through ethnography, exploring the methods and potentials of visual anthropology. In doing so, I leave an engagement with the literature of phenomenological and existential anthropology for another place. Likewise, I do not use this article to address the literature around performance theory, embodiment or place. 
musical synthesis, consciousness of the body does not intrude on the flow of making. I also suggest that stillness can be a tangible quality for musicians, which is identified, understood, practised and striven for in order to achieve the level of artistry required for professional musical performance.

\section{Building an Argument through Both Film and Text}

In Part One of this article, I discuss several sequences of film footage edited from ethnographic audiovisual material that each contribute to the project of showing and knowing stillness. I reflect upon filming observationally and processes of editing, discussing some of the ways in which those processes have helped me to better understand musicians' experience and practice. Following this, I draw on the presented material to make connections to further explain stillness (Part Two). I introduce some other ethnographic and anthropological material that has a bearing on developing an understanding of stillness in this section.

I intend to stick close to the ethnographic material in visual and other forms in order to explore practices and experiences that were an important part of music making for the musicians I worked with. Using a montage technique and aesthetic to build up a picture from a variety of sources, I aim to give a sense of stillness as a skilled practice, what it entails and its significance for musicians. It is my hope that this will provide one platform for reflection on current issues and debates in the areas of visual, digital and sensory anthropology. In particular, I wish to contribute to the current project of the sub-discipline of visual anthropology to explore and examine how using audiovisual techniques and technologies might transform, enhance and work in juxtaposition with more conventional methods in anthropology. I intend my work to be read, viewed and conceptualised in a filmic as well as a textual mode - as a kind of cinematic argument. This will allow me to incorporate the filmic and the textual, the conceptual and the sensory, the inter-subjective spaces of being and the analytical and expository directions of meaning, and to build them into an overall synthesis. ${ }^{6}$

The approach I take is developed through engagement with the texts and films of visual anthropology, and through my research using audiovisual technologies. Doing anthropology with a video camera in its most fundamental practical aspects most closely associates with phenomenological methodologies and existential anthropology. These bring us from 'abstract questions concerning objective knowledge of the world to existential questions concerning how people are actually living in the world of objects and others' ${ }^{7}$ It is from this

6 David MacDougall makes this distinction between meaning and being, linking them to different kinds of knowledge, both conceptual and perceptual. MacDougall, D. 2006, The Corporeal Image: Film, ethnography and the senses, Princeton University Press, Princeton, NJ, pp. 5-6.

7 Jackson, M. 1996, 'Introduction: phenomenology, radical empiricism, and anthropological critique', in M. Jackson (ed.), Things as They Are: New directions in phenomenological anthropology, Indiana University Press, 
methodology - 'a way of according equal weight to all modalities of human experience ${ }^{8}$ - that my research and approach to anthropology emerge and develop.

There are a variety of ways in which visual and audio technologies can be incorporated into fieldwork, depending on the research project and the approach of the researcher. My aim in taking a camera to Vienna was to film material that I would later edit into an ethnographic film. David MacDougall writes that before filmmakers can edit images, 'they have had to film them, and this has required looking ${ }^{\prime} .{ }^{9}$ Looking while filming holds its own analytic sense, separate from conceptual thinking. This careful looking is not so much about concentration as 'being attentive and free of distractions' ${ }^{10}$ Using a camera to do anthropology, then, allows for an alternative engagement with people and place, one that enriches understanding of sensory knowledge and allows reflection on the meaning of observation itself for anthropology. ${ }^{11}$ David MacDougall writes: 'To look carefully requires strength, calmness, and affection. The affection cannot be in the abstract; it must be an affection of the senses.' ${ }^{12}$ My intent, then, was to engage with visual anthropology primarily through observational cinema. This has several important implications that I introduce here and work with in this article. The first is that observational cinema prompts a stance from the ethnographer that centres on intense, engaged and specific relationships with people as they go about their lives. This means having to be in place in a sensory way. The senses and affect are therefore integral to both developing and communicating my research. Another aspect is that film itself offers a material engagement at both filming and editing stages that holds its own analytic potential for anthropology.

\section{Part One: Recognising Stillness}

More than any other medium of human communication, the moving picture makes itself sensuously and sensibly manifest as the expression of experience by experience. A film is an act of seeing that makes itself seen, an act of hearing that makes itself heard, an act of physical and reflective movement that makes itself reflexively felt and understood. ${ }^{13}$

Bloomington, pp. 1-50, at p. 19.

8 ibid., p. 2.

9 MacDougall, The Corporeal Image, p. 6.

10 ibid., p. 7.

11 The meaning and significance of observation for ethnographic practice are something that Anna Grimshaw and Amanda Ravetz pursue in their recent book: Grimshaw, A. and Ravetz, A. 2009, Observational Cinema: Anthropology, film and the exploration of social life, Indiana University Press, Bloomington.

12 MacDougall, The Corporeal Image, p. 7.

13 Sobchack, V. 1995, 'Phenomenology and the film experience', in L. Williams (ed.), Viewing Positions: Ways of seeing film, Rutgers University Press, New Brunswick, NJ, pp. 36-58, at p. 37. 
Film-work, in my research, has been an important process for developing an understanding of musicians' practices and experiences of music making. In developing this understanding of playing music and the associated concept of 'stillness', filming held more significance than I had imagined. My use of film, particularly here, became a way to 'vision' my field and to manifest 'experience by experience'.

One of the difficulties of giving clarity to the concept of 'stillness' has been the problem of providing a description, in words, of a concept that is not directly articulated in that way or any other by musicians themselves. The concept is thus elusive. There is a sense that the more you talk around it, the more difficult it becomes to maintain a feeling of its importance for musicians. Like many of the meaningful aspects of music and music making, stillness is beyond words alone. In my own anthropological practice, I have had the opportunity to discover and explore this through a combination of film and text-based thinking.

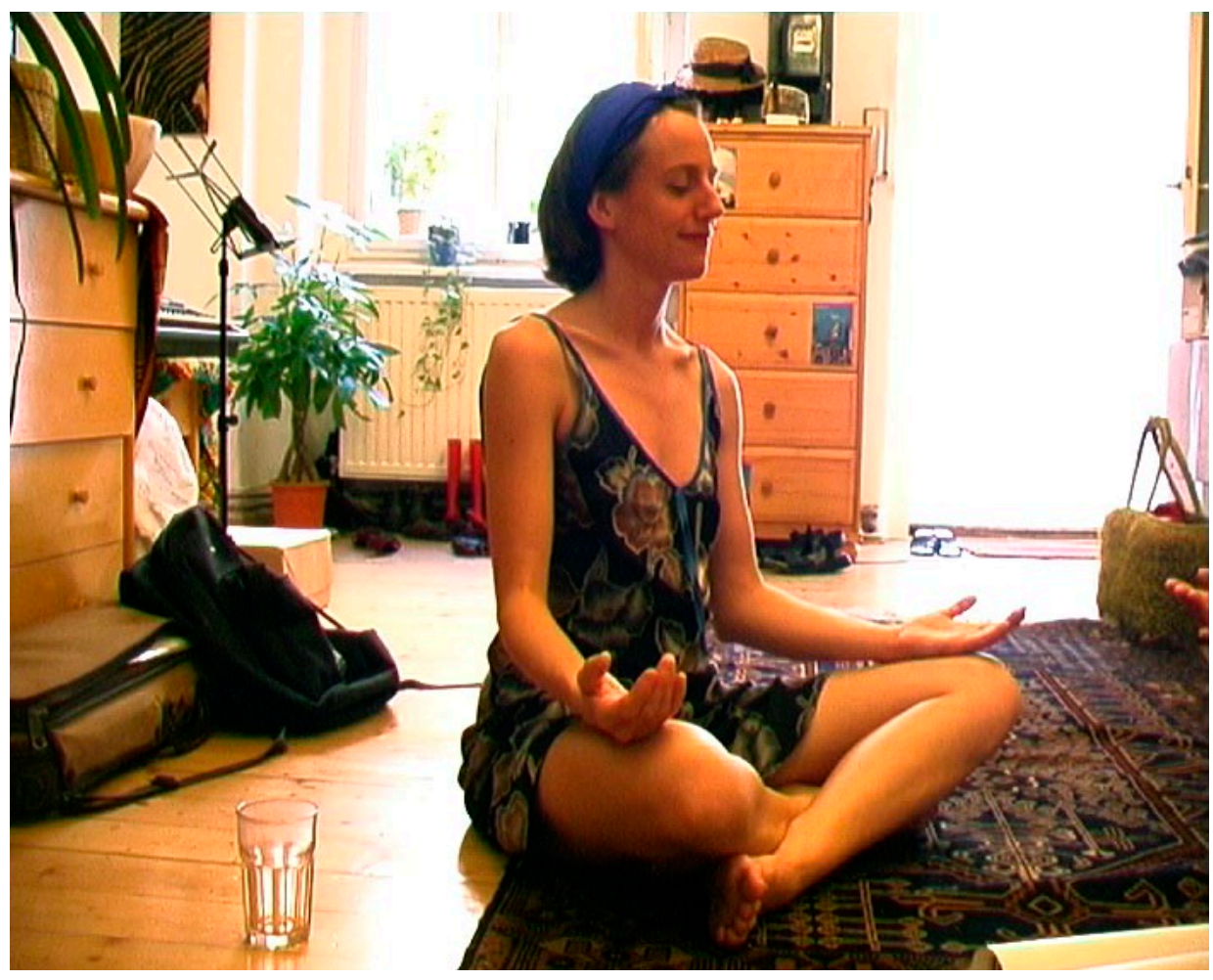

Figure 2 Still image from Meditation Sequence

\section{View Sequence Two: 'Meditation'14}

14 View associated media files via the ANU E Press website at http://epress.anu.edu.au/titles/humanitiesresearch-journal-series/humanities-research-vol-xviii-no-1-2012 
This meditation sequence is the second sequence to view. The filming has taken place inside Daisy's apartment. Although the interior is small, this scene constructs a space that is connected to a wider journey. As the sequence plays out, the meditation is associated with a musical performance, which resonates with the attitude practised and conveyed during the meditation.

During my stay in Vienna, Daisy found a meditation teacher who she really loved. She had sessions with the teacher at both her teacher's premises and her own apartment. A number of times, Daisy invited me and one other friend to go along. At that time in her life, meditation was very important to her. She said that meditating gave her more energy and a sense of focus that allowed her to stay fully involved in her music-making projects and activities, seeing them through right until the end. Meditation helped her to maintain attention and motivation throughout a particular project. And through meditation Daisy felt that she was even more successful in her aim of 'staying in the moment' while performing.

I was struck by the atmosphere of quiet attention during these meditation sessions and very much wanted to include this in my filming of Daisy. It was rare to spend time with Daisy when she was not working energetically in one way or another. While she did spend time alone, cycling and jogging, and very much enjoyed the space this created for herself, those activities were difficult to film in process. She emphasised to me the importance of maintaining such a space in her life and the feeling this gave her. She was also protective of this space.

The filming of the meditation sequence did not come about as Daisy and I had envisaged, as the teacher was uncomfortable with the idea of being filmed; however, she was happy for me to film only Daisy while she was leading the meditation session. At the time, I was pleased to be able to film some of the quieter moments in Daisy's life, particularly in order to provide a contrast with the active, busy feel of the other filming I had done. In part, I did this in order to enhance (filmically) the significance of her energetic engagements with life.

\section{Processes of Filmmaking and the Making of Anthropological Knowledge}

Watching, I breathe again.

Breathe in the rhythms of meditation.

Deeply, with awareness and relaxed concentration. 
This description of a filming moment was written as I watched my rushes. ${ }^{15} \mathrm{I}$ have included it here to emphasise the importance of the rhythms of film by giving a sense of the rhythm of breathing deeply. It was in reviewing the rushes for this sequence, and in making a rough assembly of shots, that I recognised the significance of 'stillness' ${ }^{16}$

\section{Filming and Viewing}

This meditation footage can be experienced in two ways that are significant for this discussion. The first promotes an experience from within, a visceral engagement with the meditative moment. This ability of film to give a sense of being there, a visceral connection to what we view, is connected to film's mimetic possibilities. ${ }^{17}$ The second is to take a more distanced perspective from which to focus on the scene before you (as a viewer) and perhaps notice the stillness of the camera over the time of the shot. The camera is hand-held and the footage conveys my own involvement as cameraperson in the meditation. When I edit the footage, I take a different perspective: viewing the material from that distance allows for analytical reflection. This perspective allows me to reflect on what is communicated through this shot, for example. The film material thus became a way to reflect on a given activity both from within the experience of it and from a more distanced position. As film viewers, in these moments of meditation with Daisy, we are able to join her breathing and enter with her into the rhythms of her world. This same quality is one I recognised in other material too. For example, it was a quality that was clear in some performance footage and could also be discerned amongst the repetitions of phrases in moments of instrument practice, rehearsal and improvisation.

\section{Viewing My Rushes}

Viewing rushes in preparation for editing was a process of engagement through repeated watching and logging. ${ }^{18}$ The aim of this was to gain a greater level of

\footnotetext{
15 Rushes are the raw, unedited footage of a film.

16 I had written a little about this quality of stillness in my field notes; however, editing and viewing my film material and associating that with thoughts and descriptions in my field notes, as well as snippets of conversation with musicians, were what drew out the significance of this for my anthropology. A discussion with Amanda Ravetz helped me cement this, too. Amanda had viewed my first rough cut and also recognised stillness as an important quality in my filming with Daisy.

17 Laura Marks' book The Skin of the Film discusses this. Marks, L. 2000, The Skin of the Film: Intercultural cinema, embodiment, and the senses, Duke University Press, London. See also Grimshaw and Ravetz (Observational Cinema, pp. 134-6, 139), who discuss how, in their words, 'Taussig's recuperation of the mimetic (following Benjamin) becomes valuable in understanding the unusual dynamic at the heart of observational work' (p. 139). Taussig has written that ' $[t]$ he wonder of mimesis lies in the copy drawing on the character and power of the original, to the point whereby the representation may even assume that character and that power'. Taussig, M. 1993, Mimesis and Alterity, A Particular History of the Senses, Routledge, London, p. xiii. 18 Logging is a process of recording shots in order to keep track of filmed material. I would record details such as time code, reel number, scene, location, participants, subject matter, quality and kinds of shot, and significant dialogue.
} 
familiarity with the material from which the film would be crafted, leading to an emphasis on the filmic qualities of the material. I have argued elsewhere that film enables an engagement with aesthetic presence and the sensual realities of life as a professional musician. ${ }^{19}$ The process of filming, viewing and editing my rushes made it possible to reflect upon sensory presence in the music world, the ways in which musicians work with perceptual knowledge, and to appreciate the more affect-oriented aspects of music-making activities.

An example of this is when I viewed and reviewed my rushes of Daisy and Mily performing a piece of Irish music and felt moved. I was caught up in the music again and again. In playing this piece, Daisy (who played the principal melodic line) was able to convey a feeling of sweet calmness, which would sometimes bring tears to my eyes. In this piece, I recognised the stillness that was also evident in the meditation footage. In the performance, that stillness had been accessed by the musicians and especially could be seen in and felt through Daisy's face, in her posture, balance and movement and in the strength of her playing. In contrast with other ways of relating, this showed stillness to be strongly centred in and through the body.

One of the contentions arising from my research with musicians is that it is through living a musical life that Daisy and other musicians constitute the self through which they are able to 'just be' in performance and thus perform at their best. In this, their lives can be seen as a continuous striving towards a kind of being that can be difficult to reach.

There are many things that can get in the way of 'just being' in performance. I was told often enough of how thinking could get in the way of doing. In performance, it is particularly important not to over-think, since thinking can so easily hinder playing. It is also important to not try to do too much - that is, to put too much effort into playing perfectly and brilliantly. It seems that both of these things can hinder fluidity and liveliness in performance.

At the beginning of my film, Being Daisy, Daisy tells us that 'on stage the most important thing is to be nothing [other] than yourself' ${ }^{20}$ She is in a cafe, relating to me how the experience and effect of a particular performance were transformed by thinking in different ways. When Daisy, Mily and John had played their concert on the Saturday prior to our conversation, she had made an experiment in which they had played the same piece twice, she had used the same techniques and played all the same notes - 'I was only thinking in different

19 In my doctoral thesis: Moore, P. 2010, Living a musical life: musicians, music-making and the creation of space in Vienna, Thesis, Granada Centre for Visual Anthropology, Department of Social Anthropology, University of Manchester, Manchester.

20 Moore, P. 2009, Being Daisy, [50 mins], Granada Centre for Visual Anthropology, University of Manchester, Manchester. Filming and editing audiovisual material were central parts of my doctoral research. Much of this work was directed into making the film Being Daisy, which forms an integral part of my doctoral thesis. 
ways', she said. The first time she had thought of herself as nothing special, not trying to do or be anything other than herself: 'just doing my thing.' The second time she had thought of herself as an incredible violinist, a performer who would make the music touch her audience through the power she would impart. During this conversation, Daisy asks me to guess which performance was better. Her answer is the first one, where she is 'just doing her thing' and not trying to be anything special. This is a major discovery for Daisy, which she makes and tests again and again.

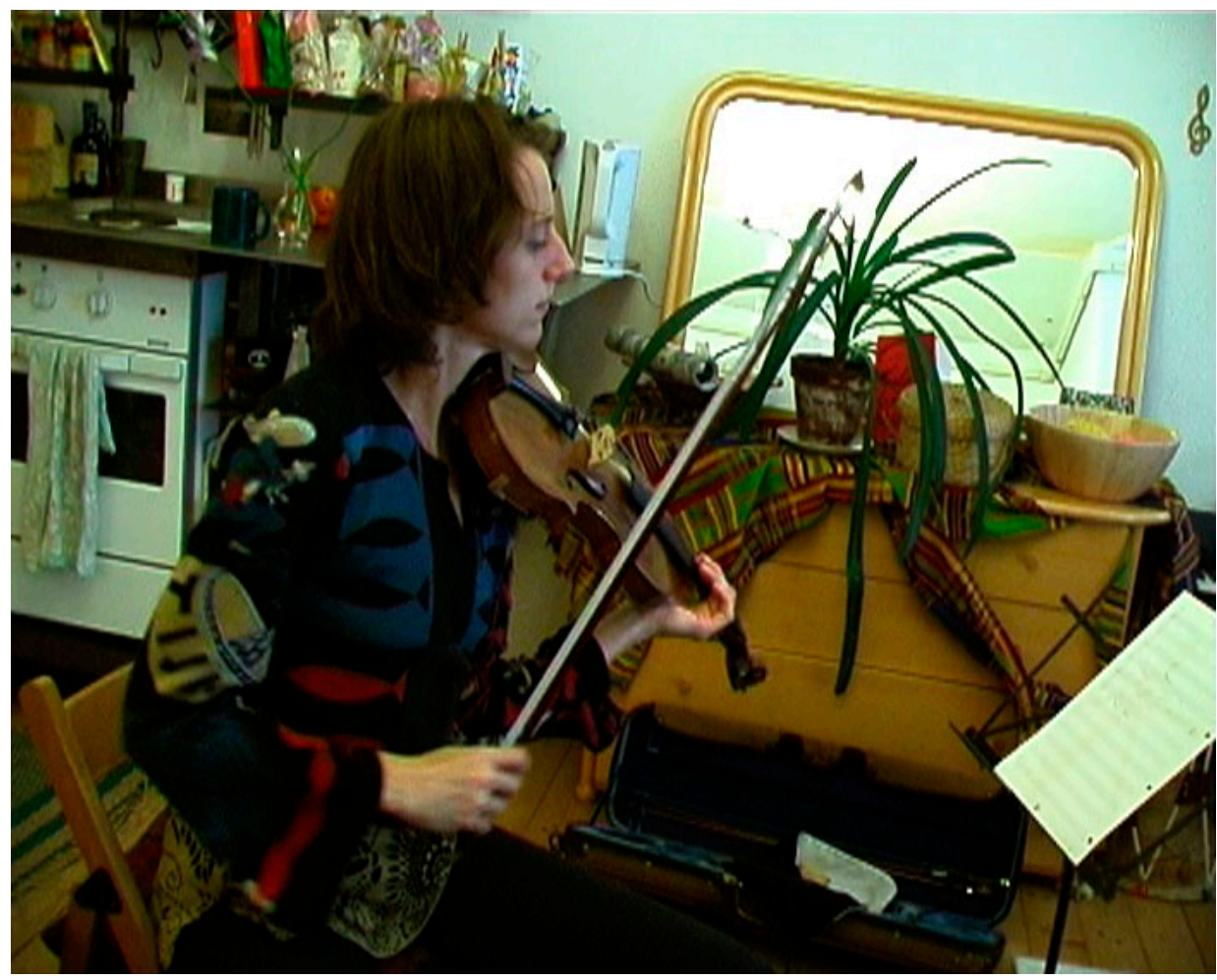

Figure 3 Still image from Composing and Practising Sequence

\section{View Sequence Three: 'Composing and Practising'21}

The third sequence is one in which Daisy - again in the small space of her own apartment - works on some music she is writing and practising.

In this scene, Daisy is improvising, composing and practising phrases as a way of working out and working through her composition. Her activities are always mediated by her relationship with her violin, even to the point where, when she

21 View associated media files via the ANU E Press website at http://epress.anu.edu.au/titles/humanitiesresearch-journal-series/humanities-research-vol-xviii-no-1-2012 
leaves it carefully on a chair as she leaves the room, its presence clearly marks Daisy's own absence from the practice space. The violin on the chair emphasises feelings of silence, absence and loneliness, simultaneously marking the violin as a familiar presence. The composing scene conveys a sense of concentrated activity - a concentration that Daisy uses to stay on task, despite interruptions through phone or fax.

\section{Editing}

The process of editing complemented the process of filming observationally. This was a way to explore time and relationships and to make connections. The process was both intuitive and serendipitous. In the edit suite, I constructed the scene of meditation around my own meditation with the camera. Something of my felt experience of this meditation comes through in the footage - marked by my own stillness while filming and the qualities of our shared breathing. During this meditation scene, both Daisy and I were accessing stillness. Moreover, this was a shared experience. This became more significant to me once I viewed this meditation in relation to other filmed moments. For example, I recognised this quality again in many of Daisy's performances while viewing and reviewing my rushes.

Working with the camera and with the tools of editing gave an awareness of different rhythms, simultaneously present. There were rhythms on different scales: that of a whole practice session, as against the different tasks and segments within that session. There were audible rhythm and inaudible rhythm, internal and external rhythms, rhythm that aided concentration, rhythm that developed through working with others, and competing rhythms that could as easily disrupt as enable. Feeling rhythm was an indication of being in time, as well as a place from which to explore time as it is experienced and lived in music worlds. Through stillness, there was a sensual awareness of the rhythms of a place, to which a performer could be responsive. Making music in a concert situation was, for musicians, a lot about tuning in: feeling, capturing, making, matching and attaching rhythms within a particular location towards a shared experience.

Working with film constitutes a continuation of fieldwork because of the way that film renders being. ${ }^{22}$ Through editing one can undertake a kind of intensive, immersive ethnography that is different from reviewing field recordings and notes. Working this way, the material comes alive in a different way, because it involves a continuous re-immersion in the moments of filming, which is combined with the distance of time and the hyper-reality of multiple

22 That film can render being is something that is suggested through the writings of David MacDougall; see, for instance, The Corporeal Image, p. 5. 
repetitions. In editing, although I compressed time, I aimed to achieve a fidelity to the overall experience of being with Daisy and other musicians. The edited sequence above resulted from my engagement with the rushes and attempt to reflect the sense of activity that I felt when watching Daisy work.

Playing with the rushes of Daisy's composition and practice session enabled me to think through the activity of repetitive practice and find out more about this activity and its place in music making for musicians. In doing so, I used editing as my tool. I altered real time, cutting into the repetitive practising of the day and layering shots of these repetitions almost randomly together. I tried imposing rhythm (cutting every few seconds) and, additionally, cutting into a shot through feeling the internal rhythm of the playing, and placing a new, random shot at that spot. The result was often jarring, but interesting, because it highlighted how even in the repetitive nature of disjointed practice, there is a sense of rhythm. This rhythm is both disrupted and highlighted by my cutting. Sometimes when I repeated the same material again and again, however, I reestablished a rhythm of my own.

In the sequence presented above, I intentionally spent time finding jump cuts that would work to show time passing, conveying in the language of film something of the length of time musicians spend at private practice, without losing a sense of the coherence of the practice session in felt terms. This highlighted several things about rhythm - most importantly the difference of working with rhythm imposed from without as opposed to felt from within. This process of working through ideas about practice and its importance in music making enabled me to highlight and grasp something that was otherwise difficult to articulate about the felt experience of being a musician. This was significant for my overall understanding about living as a professional musician in Vienna.

\section{Part Two: Making Connections}

In this section, I make some connections between the film sequences discussed in this article and other material from my fieldwork. I make these connections, montage-like, in order to build up a picture of the relationships between thoughts, feelings, actions and intentions around stillness: of being-in-themoment; of being yourself; of not being negative, not being lethargic; of letting go of doubt; of being relaxed, as a kind of heightened awareness and of attending with and to the senses. 


\section{Introductory Sequence: Being yourself}

In the conversation in the Introductory Sequence, Daisy talks about how she has to 'be herself' in order to give her strongest performance. In this section, I continue to explore what is meant by 'being oneself' in this context, explicitly connecting what I am referring to as 'stillness' to musicians' talk of 'beingin-the-moment', 'being there' and 'being oneself'. Such ways of referring to musical experience in the context of shared activities and discussions about music making were not uncommon amongst the musicians with whom I worked. As I see it, stillness - as a practised skill associated with a particular way of being-in-the-world - is referred to by such talk. Conversations like the one in this first sequence were one way musicians could recognise, learn and develop this stillness as a performance skill. Informal conversation thus contributes to musicians' knowledge and understanding of how to be a professional musician.

Being-in-the-moment requires a particular kind of concentration-an attentiveness to the body in place, combined with a focus or direction gained in the action of playing itself. Stillness helps musicians to achieve extended concentration that is free from distraction, where, as Margaret puts it, 'nothing is inhibiting that flow'. One aspect of remaining free from distraction in playing stems from the ability to overcome mistakes in a context in which musicians aim to play perfectly. It is important in performance not to let having made a mistake intrude into consciousness. In one of our filmed discussions, Daisy talks about the importance of 'forgiving yourself'. I asked her whether the ability to forgive oneself makes for a good performer. She thought it must, because, without the ability to forgive yourself, you cannot manage to 'be there'. For Daisy, these abilities - to 'forgive oneself' and to 'be there' - are very important not only in performance, but also in the practice of a professional musician's life.

Daisy: Once you're there, you also feel, for example, 'OK, I have to practise for this concert', and you will. You'll really practise for it and you'll be able to feel what you need to do because you know where you want to be. So you know, 'I want to play this great concert and I need to do this and this', and you know this knowledge of what is needed to do. You see...I don't know what it means to see yourself as who you are, because we are not something specific. But when you're living there, I think you do see yourself for what you are. It's just nothing you can [pin down] at all. You wouldn't say 'Oh, I'm particularly creative' or... nothing like that. It's just you're being there and then you can feel, you can just feel the things that are needed for your goals or for anything you want in your life, and you do those things, you follow them.

Professional musicians in Vienna are commonly thought of as creative, artistic persons who are able to be masters of individual self-expression, but 
the musicians I worked with were often sceptical about or even downright dismissive of this idea. Nevertheless, it was clear that many of the musicians came to and stayed in Vienna because they were in an environment that enabled music making of a high standard and through which they gained inspiration for their playing. During my fieldwork, it became clear that 'being yourself' was seen as an ability and attribute of the creative individual and as a concrete achievement of supportive groups of friends. In fact, perspectives on work and practice held an everyday importance for musicians that far outweighed more abstract and idealised considerations of creativity and talent. So, despite the fact that a strong association existed between understandings of Western classical music and ideas of individual talent, inspiration and genius, the professional musicians I worked with were focused on much more concrete aspects of music making in their daily lives. Musicians facilitated the making of vibrant spaces for music making through the level of support they offered each other by, for example, involving themselves in the performance occasions of others. This was one of a number of significant social activities that sustained the working friendships of musicians.

An excerpt from a conversation recorded during my fieldwork speaks to this supportive environment. It was through such working friendships that the creative individual existed.

Yu: I mean, one thing I've noticed since coming to Vienna is how much of a positive effect-

Margaret: - a positive environment can have.

Yu: Yes. Absolutely! And [pause]... before I was quite allergic to praise, and now I can give it sincerely and I can receive it sincerely too. And it does wonders. It really, really, really does amazing things.

\section{The Meditation Sequence}

Throughout the filming, I took time with the camera, looking, listening and attending with the senses. I understood and used my body as integral to the filming, to the research, and, therefore, to my techniques of ethnographic and anthropological understanding. Filming observationally, whatever else it becomes, is initially a site-specific enterprise, an engagement that is synthesised in the moments when the camera is on. In holding my own camera, that is how I experienced it. Often, I detected traces of this sensibility on tape-for instance, the sensibility that enabled us as viewers to be with Daisy as she meditates.

Part of my aim in including this meditative sequence is to convey something of the experience of stillness through the communication of 'experience by 
experience' ${ }^{23}$ In the juxtaposition of Daisy's meditation with a performance by Mily and Daisy's group, Son Dos, stillness as 'being-in-the-moment' is palpablesomething that can be seen, felt, recognised and connected to. My rushes of the meditation session also contained moments during which this kind of being was disrupted. For example, at one time, a participant in our meditation session stood up and moved around. The recording on tape shows the change when the sensory awareness and attentiveness of stillness were disrupted. For one, the hand-held camera work became unstable for a while because this change in attentive awareness prompted me to shift around a little. At that moment of disruption, Daisy also moved, becoming aware of her shoulder muscles - she put her right hand to the shoulder where she would normally rest her violin. For viewers of the footage, this prompts a change of perspective, and they become less a participant in the flow of the film material, just as Daisy had become more aware of her own self as meditating, and had then to re-engage the skill of being-in-the-moment to continue the meditation.

\section{The Practising and Composing Sequence}

During a different activity - that of composing and practising — Daisy's overall focus and concentration were maintained over some hours. It was a concentration that was present on the scale of the work session as a whole. While at the fax machine or talking to me about composing, Daisy demonstrates one way in which she maintains that concentration, as she directs her attention back to the work of the session, thinking about the style and the mood of the piece and the way she can use the violin. Here, she attends to how she feels, and connects to the practice she is doing.

In this sequence, as in other parts of the material I have presented, I use the camera to attend to place, to interact with people in place and to notice things that I otherwise might not have noticed. For example, in this sequence there is a driven energy to the activity. This was a quality that was present in Daisy's everyday life, bound up within her person, in and through her relationships. Editing gave me the ability to materially work with practising and composing. It thus gave me a way to understand how musicians wove the sensibilities of making through their lives. In the film sequence, the quiet times of notating are contrasted with the material thinking through of the improvisation and practice activities. The rhythm and discontinuity of this are emphasised through my playfully editing in the same manner as the imaginative crafting of the composing scene.

23 Sobchack, 'Phenomenology and the film experience', p. 37. 
In placing footage of a concert performance after the meditation sequence in the finished film, Being Daisy, I was able to create, at one and the same time, an intensiveness and extensiveness to the communicative activity of performing. This material can be connected to Daisy's description of the relaxation that is important for a strong performance, in which you are 'incredibly aware'. The playing posture, balance and poise of the musicians stem, I would suggest, from their skilled working with stillness. The bodily awareness of musicians is evident in the conversation at the beginning of this article. Yu's 'you're in the negative' hand movement indicates the bodily engagement in conversations and the materiality of ideas. As a practice, stillness can be associated with a kind of poise in the world that incorporates a proprioceptive awareness of the body in the environment. ${ }^{24}$ Once achieved, stillness is invigorating; however, stillness rarely seems to come easily. It is elusive and perhaps never quite grasped, thus requiring constant pursuit, a constant balancing in activity. Part of the skill of stillness is to maintain the right balance of concentration, relaxation and energy in changing circumstances.

Musicians' skilled bodily awareness, specific to their own music making, allows them to bring parts of their body to awareness when required - often without conscious thought, but with a good deal of attention. Musicians are thus aware of their bodies in daily activity. This can be especially the case with the activity of playing, where feeling the body and playing an instrument are interlinked. In his discussion of playing his cello, Tim Ingold writes 'to play is itself to feel' ${ }^{25}$ He argues that feeling, rather than being an index of inner emotion, inheres in his gestures and includes such things as the pressure of the bow against the strings and the vibrato of his left hand.

While playing, musicians work to mutually constitute and transform being, body and space within the sensuous materiality of the environing world and in the contingencies of the activities of playing. Their skill in doing so lies in their ability to bring into use the right combination of perception, thought and action at exactly the right moment. In his discussions on skill, Tim Ingold

\footnotetext{
24 I suggest here that stillness can be related to the sense of proprioception. To explain this further, I cite Thomas Csordas, who writes that proprioception is 'our sense of being in a body and oriented in space'. Csordas, T. J. 1994, 'Introduction: the body as representation and being-in-the-world', in T. J. Csordas (ed.), Embodiment and Experience: The existential ground of culture and self, Cambridge Studies in Medical Anthropology No. 2, Cambridge University Press, Cambridge, pp. 1-26, at p. 5. I also cite Pedersen et al., who define proprioception as 'the movement and position sense' and consider it to be 'synonymous with the ability to detect, without visual input, the spatial position and/or movement of limbs in relation to the rest of the body'. Pedersen, J., Lönn, J., Hellström, F., Djupsjöbacka, M. and Johansson, H. 1999, 'Localized muscle fatigue decreases the acuity of the movement sense in the human shoulder', Medicine \& Science in Sports \& Exercise, vol. 31, no. 7, pp. 1047-52, at p. 1047. Musicians use proprioceptive skill to respond through their playing and in the flow of activity to the specific and constantly changing circumstances of performance events.

25 Ingold, T. 2000, The Perception of the Environment: Essays in livelihood, dwelling and skill, Routledge, London, p. 413.
} 
writes that the skilled practitioner 'is able continually to attune his movements to perturbations in the perceived environment without ever interrupting the flow of action' ${ }^{26}$ This requires, simultaneously, an attention to the body and an experience of its absence (lest such an awareness interrupt the flow of playing).

Stillness takes discipline in order to maintain awareness in the flow of action and changing circumstance and, within that, to direct attention where needed and bring the appropriate skills into use at the right moment in rhythm and with timing. Although I associate stillness with 'being-in-the-moment', it cannot be characterised as a short-term, frivolous, hedonistic attitude of 'thinking only about the now'. It is, rather, an extended temporality. Stillness is a practice that allows the incorporation of a lifetime's worth of experience and skill into the improvisational circumstances of live performance. Musicians work hard to embody their musical skill through rehearsal and individual musical practice because embodied skills no longer demand continuous conscious attention.

In his book The Absent Body, Drew Leder discusses the paradoxical nature of bodily presence, suggesting that our experience of the body is that it is mostly absent to us. 'It is often assumed', he writes, 'that this dualist [Cartesian] paradigm is shaped by ontological commitments at the expense of attending to lived experience' ${ }^{27} \mathrm{He}$ argues that a phenomenological account of bodily absence would suggest otherwise. In this, he challenges both our historical understandings of the body and our more recent critiques of these. Musicians, I would suggest, constitute a different case. In their practice and rehearsal, musicians attended explicitly and expertly to the body in order to pass their knowledge to the level of habit - where they no longer have to attend to bodily presence. In this sense, they are actively training the body to be absent through their attention to lived experience. Sigaut has something similar to say on this kind of technical expertise. He writes:

The fading of knowledge in the process of assimilating it, or, better, literally embodying or incorporating it, is an essential feature of effective action and thus of technics...Learning is not complete until the transmitted patterns of action have become automatic...[this] has often been compared to a black box, which means not only that you can no longer see how it works, but also that you no longer need to know. An expert's nervous system is an even more impenetrable black box. ${ }^{28}$

Their ability to incorporate knowledge in this way is an expertise that is central to musicians' everyday practice. In order that their experiences of their bodies

26 ibid., p. 415

27 Leder, D. 1990, The Absent Body, University of Chicago Press, Chicago, p. 3.

28 Sigaut, F. 1994, 'Technology', in T. Ingold (ed.), Companion Encyclopedia of Anthropology, Routledge, London, pp. 420-59, at p. 438. 
are absent to them, they need to be attentive to their bodies. In relation to Leder's phenomenological account of bodily presence, this expertise suggests a significant way in which being a professional musician might constitute a very particular way of being-in-the-world and relating to others while playing.

Leder argues for a phenomenology of the body that uses the idea of fromto orientation to explain ways in which our body is not present to us in our everyday experiences of being-in-the-world. ${ }^{29}$ The body, according to Leder, only becomes present to us through experiences such as pain. While musicians experience this also, playing music requires musicians to skillfully presence the body in order to play and perform to the best of their ability. I would suggest that it is this skill of awareness and 'presencing' that allows them to make the minute and continual adjustments to 'tune in' to each other, to 'be together' in the music and respond flexibly to realise a musical performance.

The delicate balance that musicians have to achieve between perception, thought and action is highlighted by the following story: during rehearsal, one member of a string quartet kept messing up his particular part. He started off a section of the piece playing on the offbeat and was meant to maintain this rhythm in counterpoint to the others in the group, but somehow, he ended up playing on the beat. The other group members found this amusing and played a trick on him. They deliberately drew his attention to his playing during that part of the piece, knowing that if he thought about it and if he had to start consciously trying to keep his playing in time, he would inevitably 'stuff up'. One of the others told me afterwards that they know 'he can totally do it' as long as he does not have to think about it. They were not at all worried that he would not 'get it' when he was in performance.

The coming together in skilled practice of thinking, doing and feeling presents a challenge to Leder's formulation of bodily presence. This is because, in the flow of skilled music making, the musicians aimed to simultaneously hold their bodies both present, through a kind of loose attention that became focused when needed, and absent, through a belief and trust that they would be able to 'just do it'. For one of my friends, Tristan, this was an ideal, although not a necessity, for music making. He told me that he was always striving towards 'being in the body' while playing, because you can be 'a stronger player that way'. The first thing one must do to be in the body, in his account, is to 'be aware'. I told him of my interest in the juncture at which skilled musicians are able to bring things to consciousness within the flow of playing at those moments when they most need them. Tristan agreed that this is a skill that musicians have to learn. I suggest this skill is based upon a perceptual knowledge, which becomes so embedded in bodily praxis as to constitute an intuitive skill - one that cannot 
be wholly articulated in words, whether spoken or thought. This skill is one that works best, according to Daisy, Tristan and others, when you are relaxed and happy with yourself as a musician.

To 'be there' one has to have confidence and let go of doubt, while still holding an openness to possibility. The confidence referred to is, for musicians, about knowing you can do it - that is, knowing you can play and perform the selected material. If stillness is thought of as a crafting of the moment, the confidence involved is an implicit understanding that one has the ability to craft in performance. One of the ways in which musicians gain this confidence is through practising with their instrument. During practice time musicians do exercises that improve their agility, they repeat certain passages over and over in order to understand and learn those passages and thus improve their performance.

'Practice', Yu says, 'is only to get rid of this fear'.

Daisy agrees: 'It is about getting rid of the fear and it's about getting to know the pieces, actually.'

Yu: Well...yes. But after a while it's about getting you to the stage where you have the confidence to go out and say 'Look, I can do it'.

Daisy: And it's funny...in a way I never think about confidence but actually it does seem to have something to do with it because I only think about only being there now-but of course being there now means you've let go of any doubt.

Yu: Of course.

\section{Crafting the Moment}

In this article I have drawn together diverse pieces of ethnographic material, filmic and written, in order to explore the concept of 'stillness' particularly in performance contexts. I have suggested that this stillness is a skilled practice and a tangible quality for musicians, which must be identified in some way, understood, practised and striven for in order to achieve the level of skill required for professional musical performance. I show the significance of stillness by juxtaposing, contrasting and connecting different material that arose from the process of filming. In the process, I identify it as a skilled practice in which years of musical practice and experience, and the diversity of skills that this involves, are gathered together in the moments of playing. Stillness, then, is configured, not as an absence of activity, but rather as the ability to concentrate on a diverse history of activity, and tailor it to the task at hand. It is a skill of bringing things into the moment and settling into the moment where perception and attention are gathered for the task at hand. 
Through stillness, there is a point of synthesis of different kinds of knowledge and know-how, ideas and feelings, passion and abstract thought. There are connections made between actions, perceptions, thoughts and intentions that only emerge with stillness, facilitating lively and communicative performance. I also suggest that stillness has a broader significance in the lives of the professional musicians I worked with, since practising stillness constitutes a particular way of being-in-the-world that is part of their everyday experience.

I have aimed to show what is meant by stillness by using film as part of my anthropological research. I juxtaposed and connected different film sequences with other ethnographic material to allow the reader-viewer to experience something of stillness. Using audiovisual material in combination with text gives reader-viewers a way to know stillness, helping to make sense of musicians' conversations that include serious consideration of such things as 'being yourself' and 'being-in-the-moment'. In the context of living as a professional musician, stillness can be seen as not only a performance technique, but also a significant life skill. 